\title{
EDUCAC̄̃̃O DO CAMPO COMO ESPACִO EM DISPUTA: ANÁLISE DOS DISCURSOS DO MATERIAL DIDÁTICO DO PROJOVEM CAMPO - SABERES DA TERRA
}

\author{
Mara Edilara Batista de Oliveira* \\ Universidade Federal Fluminense (UFF), Angra dos Reis - RJ, Brasil
}

RESUMO: A Educação do Campo, hoje, é mais do que uma demanda dos movimentos sociais: ela se transformou num espaço em disputa. Essa disputa se dá, principalmente, pelo poder/controle do modelo formativo que essa educação irá ofertar. Entre essas ações estão o ProJovem Campo e seus respectivos espaços de formação, com destaque para o material didático. Como um dos instrumentos formativos mais importantes, o material didático sempre esteve em disputa, especialmente pelo controle do que será levado a cabo por meio dele, instrumento tão valioso para a formação dos sujeitos no campo. Compreendendo que Estado, capital internacional, movimentos sociais e pesquisadores da Educação do Campo disputaram conceitualmente - e, nesse sentido, ideologicamente - o sujeito que seria atendido por esse programa, acreditamos que não tenha sido um processo simples e, diante disso, temos como objetivo, neste artigo, evidenciar os discursos privilegiados nesses livros didáticos, os quais, por sua vez, acabam por negar outros.

Palavras-chave: Educação do Campo. Material didático. Uso do discurso.

COUNTRYSIDE EDUCATION AS SPACE IN CONTEST: ANALYSIS OF THE DISCOURSES OF TEACHING MATERIAL OF PROJOVEM COUNTRYSIDEPROGRAM: KNOWLEDGE OF EARTH

ABSTRACT:Countryside Education nowadays is more than a demand of social movements: it turned into a space in dispute, part of the Brazilian Agrarian Question. This dispute is mainly for power/control of training model that this education will offer in various areas/rural territories it will cover after it became a National Public Policy. Among these actions are the ProJovem Countryside Program and their respective training spaces, highlighting the use of didactic material. As one of the most important formative instruments,

"Doutora em Geografia pelo Programa de Pós-Graduação em Geografia da Universidade Federal do Paraná (UFPR, Curitiba). Professora e pesquisadora do Instituto de Educação de Angra dos Reis. Departamento de Geografia e Políticas Públicas da Universidade Federal Fluminense -UFF. E-mail: < edilaramara@gmail.com > . 
the didactic material has always been disputed, especially by the control that will be carried out through it, so valuable instrument for the formation of guys in the countryside. Understanding that State, international capital, social movements and countryside education researchers has disputed conceptually - and, in this sense, ideologically - the guy who would be served by this program, we believe that it has not been a simple process, so that we, in this article, highlight the privileged speeches contained in these textbooks, which, for your time, they deny others.

Keywords: Rural Education. Teaching material. Use of speech.

\section{INTRODUCุÃO}

O ProJovem Campo - Saberes da Terra ${ }^{1}$, que nasceu como um projeto-piloto em 2005 ainda com o nome de Saberes da Terra, foi avaliado pelo MEC e os demais órgãos responsáveis, em 2007, como um projeto que poderia ser transformado em um programa social, pondo em prática o disposto na LDB Nacional, para, assim, ser implantado nas demais regiões e estados do país.

Muitas das organizações sociais, os pesquisadores e os demais sujeitos que lutavam por Educação do Campo o viram, inicialmente, como resposta a essa demanda, que ecoava no campo há quase uma década: a construção de um projeto político educacional que trouxesse as especificidades do campo e atendesse à necessidade histórica de uma educação construída por e a partir dos sujeitos do campo, respeitando seus saberes e suas formas de vida.

Desde 1998, nessa perspectiva da construção de uma Educação do Campo, já estava em andamento o Programa Nacional de Educação na Reforma Agrária - Pronera -, que vinha ofertando educação e formação para crianças, jovens e trabalhadores rurais das áreas de assentamentos de Reforma Agrária e, mais tarde, de acampamentos de luta pela terra. Esse programa foi uma conquista dos movimentos sociais organizados no campo no Brasil, em especial do Movimento dos Trabalhadores Rurais Sem Terra - MST -, por ter sido esse movimento pioneiro na organização da educação na luta pela terra, respeitando os saberes construídos em movimento, em luta (CALDART, 2004).

No entanto, não existia uma política, nem mesmo um programa específico, que desse conta da diversidade dos sujeitos do campo no Brasil, o que mantinha as taxas de analfabetismo gritantes nos espaços rurais. Ademais, além das organizações relacionadas com a reforma agrária, surgiram outras, com essa mesma bandeira: buscar uma educação específica nessas áreas. Ficava claro, portanto, que essas taxas não decorriam somente das áreas de Reforma Agrária, visto que o camponês, 
em toda a sua diversidade, necessitava de escolas e de uma educação específica para a recriação de suas formas de vida e da sua autonomia.

O ProJovem Campo, num primeiro momento, foi visto por pesquisadores e estudiosos da Educação do Campo - os quais possuem um histórico de luta reconhecido nesse âmbito - sob a perspectiva de atender a toda essa diversidade de sujeitos no campo, diversidade essa que ia além dos sem-terra ou de acampados e assentados de Reforma Agrária. Porém, sabe-se que o Pronera não conseguia e nem tinha como objetivo atender a essa diversidade de grupos, já que era voltado especificamente para as áreas de Reforma Agrária.

Entretanto, em um contexto mais amplo de análise, pelo viés da interpretação da Questão Agrária brasileira atual, entendemos que, apesar do discurso de incorporação da demanda por Educação do Campo "desde baixo", a implantação do programa teve objetivos que divergiram dessa proposta. Consideramos que, na prática, o ProJovem Campo atende muito mais a uma demanda "desde cima", ou seja, uma demanda internacional de um padrão de desenvolvimento que homogeneíza o homem do campo como agricultor familiar, inserindo-o numa lógica de mercado, a qual vem se mostrando, muitas vezes, mais opressora que outras formas de subordinação capitalista no espaço agrário.

Essas formas de subordinação são, também, formas de controle social que encontram na educação um dos campos mais propícios, pois perpassam por formas de subjetivação política desses sujeitos. Neste artigo, buscamos desvendar os conflitos da questão agrária gerados no interior da disputa pelo controle dessas formas de apropriação, que passam diretamente por disputas da formação/ educação desses sujeitos sociais.

Para isso, analisaremos os conflitos da Questão Agrária atual por meio dos conflitos diretos no âmbito do que, hoje, chama-se "Educação do Campo", que nada mais é do que a luta concreta dos movimentos sociais por uma educação de qualidade, parte de um processo histórico. Mais concretamente, para evidenciar esses conflitos e essas formas de dominação na prática, analisaremos o material didático do ProJovem Campo, a partir da metodologia de análise do discurso. O intento é desconstruir as formas de discursos "desde cima", mostrando o que eles escondem ao marginalizar discursos "desde baixo" 3 . Entretanto, ao utilizar a metodologia de análise do discurso de Foucault (1987), o que desvendaremos e colocaremos para debate será: o que o discurso presente nos livros didáticos do Projovem Campo esconde? O que é omitido? O que deixa de ser evidenciado ao escolher determinados sujeitos e determinadas formas de produção, e não outras? 


\section{A ATUALIDADE DA QUESTÃO AGRÁRIA BRASILEIRA: ESPAÇOS EM DISPUTA}

Em suas análises sobre o campo brasileiro, Graziano da Silva (1997) considera a questão agrária como um tema ultrapassado. Para esse autor, os conflitos no interior da questão agrária brasileira foram resolvidos na construção de um "novo rural", como o autor declarou em seu texto intitulado O Novo Rural Brasileiro: "O meio rural brasileiro se urbanizou nas duas últimas décadas, como resultado do processo de industrialização da agricultura, de um ladoe, de outro, do transbordamento do mundo urbano naquele espaço que tradicionalmente era definido como rural" (SILVA, 1997, p. 1). Um "novo rural" no qual os conflitos no campo cessariam frente ao modelo de desenvolvimento do capital, o que, por fim, homogeneizaria esses espaços.

Entretanto, não foi isso que ocorreu. $\mathrm{Na}$ prática, os conflitos se acirraram e a entrada do século XXI é marcada por conflitos que vão além da luta pela terra e pela Reforma Agrária. Outras bandeiras são levantadas, as quais estão ligadas diretamente às formas de vida camponesa. Em resposta, o aparelho estatal amplia suas amarras com a criação de um conjunto de políticas que seguem não só a lógica do controle do capital, mas também a lógica do controle territorial ${ }^{4}$ (as duas lógicas, nesse caso, mais se encontram do que divergem). E a apropriação da Educação do Campo e seu modelo formativo teria papel central na formação de novos e velhos sujeitos da questão agrária: camponês versus agricultor familiar.

$\mathrm{Na}$ entrada do século XXI, esse projeto de desenvolvimento para o campo tinha dois grandes eixos de atuação: de um lado estavam o agronegócio e os investimentos voltados para a grande indústria de exportação, que tem como base as monoculturas, principalmente de soja, de milho e de cana-de-açúcar para a produção de biocombustíveis, e eucalipto para a produção de celulose - as quatro maiores commodities no Brasil. Do outro lado estava a consagração de uma agricultura familiar, construída por programas de governo, como o PRONAF, garantindo, por meio dela, a produção familiar, que viria a subsidiar, por exemplo, grandes empresas alimentícias de carnes (principalmente de suínos e aviária), produção de hortas orgânicas com selo verde, polpa de frutas para a produção de sucos engarrafados, entre outras.

Em ambos os projetos, o camponês que não garantisse o modelo de produção exigido, quantidade e forma de produção (adesão ao "pacote tecnológico" da Revolução Verde), estava excluído desse circuito e, portanto, "dos olhos" do Estado. O camponês, nesse sentido, tinha duas escolhas: a primeira era se inserir de forma precária no mercado, de modo a garantir a produção para grandes indústrias 
sob formas exploratórias desumanas e, muitas vezes, sucumbindo ao endividamento com o crédito do próprio Estado - o que, além de tudo, os forçava a se tornarem agricultores familiares, perdendo quase que totalmente sua autonomia camponesa; ou a segunda era manter-se fora desse circuito de produção, com certo grau de autonomia em relação ao Estado e às classes dominantes, mas sem nenhum incentivo financeiro para a reprodução das suas formas de vida. Nesse último caso, ele continuaria sendo o camponês que, historicamente, na formação do espaço agrário brasileiro, foi sendo excluído diante do modelo de desenvolvimento desigual e resistindo por meio de processos de autonomização.

Nesse modelo de desenvolvimento desigual do capital no Brasil, a estrutura fundiária não foi alterada e, tendo sido freada a Reforma Agrária, que havia se ampliado na década de 1990, manteve-se a concentração de terras, agora revestida pelo agronegócio, e a propriedade camponesa subsistiu por meio do modelo da agricultura familiar, ou seja, subordinando sua lógica para subsidiar o mercado. Por meio da compra da produção da agricultura familiar, as empresas estabeleceram contratos e se instalaram nas proximidades dessas comunidades camponesas, passando a extrair mais-valia absoluta dos seus produtos.

A estratégia desses grandes empresários era simples: por meio de contrato para a compra e a venda dos produtos dos pequenos agricultores familiares, não se fazia mais necessário que as empresas comprassem terras para produzir, pois esses camponeses possuíam suas próprias terras. Outro ponto importante nesse processo, que pesa em desvantagem para os agricultores familiares, é que esses empresários não necessitavam contratar mão de obra com carteira assinada, desobrigando-se do pagamento de todos os direitos assegurados por essa forma de contratação, visto que, na lógica do mercado, eles estavam comprando "apenas" o produto.

Com toda a lógica de produção captada pela Revolução Verde, outro processo vantajoso para os grandes empresários é que estes vendiam suas próprias sementes e genes para os camponeses, garantindo que a produção se mantivesse nos seus padrões. A venda de todo o "pacote tecnológico" para a produção regulava, também, a forma produtiva e a quantidade da produção estabelecida por contratos, extraindo toda a autonomia camponesa e garantindo o ganho total das empresas.

Todo esse processo se dá com o subsídio direto do Estado e por suas instituições que, escalarmente, garantiam a implantação de programas que eram peça-chave para viabilizar a produção do pequeno agricultor, como o PRONAF ou o Banco da Terra ${ }^{6}$. É o Estado, portanto, que financiava indiretamente a produção das 
grandes empresas instaladas no campo, além de promover vários incentivos e financiamentos diretos já existentes para essa categoria.

Para completar a lógica do desenvolvimento desigual, que utiliza formas de controle na produção do espaço agrário, apenas negar acesso à educação dos sujeitos do campo não era mais suficiente para o capital. Esse modelo de desenvolvimento necessitava também de um modelo de educação para essas áreas rurais, de modo a formar mão de obra específica para novos e velhos sujeitos na entrada desse novo século, que marcava grandes transformações no espaço agrário e que, ao mesmo tempo, mantinha velhos padrões de exploração das forças produtivas.

Agora as formas de dominação tinham que se ampliar a outros âmbitos das formas de vida desse campesinato, chegando à subjetividade do ser social e, nesse sentido, a educação e seu modelo formativo tinham papel central na apropriação e no controle dessas subjetividades.

Para cada um desses dois eixos do modelo de desenvolvimento para o campo - um eixo que inclui o camponês como agricultor familiar para o mercado e outro que o exclui expulsando-o e expropriando-o de suas terras -, havia um modelo de educação a ser ofertado pelo Estado. O que se observa na segunda década do século XXI é que, em nenhum desses modelos implantados, havia uma proposta de educação para a recriação e para a autonomia do camponês; em nenhum desses modelos a Educação do Campo foi ou é prioridade.

O que ficou desse modelo de desenvolvimento para o campo hoje, enquanto política pública, foram duas propostas, que são muito próximas e que se complementam, e muito pouco, ou nada, trazem do paradigma da Educação do Campo em suas bases. De um lado está uma educação mais técnica, que tem como objetivo formar mão de obra para um trabalho mais especializado, que serve ao agronegócio - educação esta que é financiada e institucionalizada pelo Governo por meio de programas como, por exemplo, o PRONATEC Campo. E, de outro lado, está um modelo de educação que privilegia a inserção da mão de obra no mercado de alimentos, fruto da agricultura familiar, a qual, para o Estado, não necessita ser tão especializada. No entanto, ela resulta no apagamento da luta e no apaziguamento dos conflitos, criando esse novo sujeito, o agricultor familiar. Como programa de governo que veio subsidiar essa formação, podemos dar como exemplo o Projovem Campo.

Sendo assim, é nessa segunda década do século XXI que podemos ver as consequências da implantação desse modelo de desenvolvimento neoliberal no campo, que, em parte, logra os objetivos da lógica de dominação do capital, mas, por outro lado, não consegue captar tudo para a sua dinâmica, fazendo com que alguns aspectos fujam do seu controle. 
A péssima notícia para os teóricos que declaravam o fim do campesinato e a urbanização do campo é que isso não ocorreu, pois, para a própria lógica do desenvolvimento do capital, fez-se necessário manter a produção no campo nos dois eixos levantados acima, o que tem como consequência imediata a resistência, os conflitos e as ações de autonomia em contraposição a esse modelo de desenvolvimento.

Assim, nesse processo de quase duas décadas, as formas de dominação de poder do capital tiveram que se reconfigurar escalarmente várias vezes, restabelecendo novas instituições de controle, construindo novas estruturas escalares ou, às vezes, negociando espaços em disputa com estruturas escalares de poder "desde baixo".

As lutas sociais no campo criaram seus próprios sujeitos. São, portanto, processos de subjetivação política que criam identidades próprias, com bandeiras outras. O fim da primeira década do século XXI é marcado pela conquista de direitos e de políticas públicas que consagram a luta por meio do reconhecimento das identidades coletivas, como aquelas associadas aos Povos e Comunidades Tradicionais. É o caso, por exemplo, da criação da Comissão Nacional dos Povos e Comunidades Tradicionais - CNPCT -, em 2006, e da Política Nacional de Desenvolvimento Sustentável dos Povos e Comunidades Tradicionais - PNPCT -, em 2007, por meio do Decreto no 6040 da Constituição Federal, a qual apenas se consolida nessa segunda década, garantindo a implantação de projetos e financiamentos para esses territórios.

Nessa segunda década, os movimentos sociais de luta pela terra tiveram a mais baixa representatividade em ocupação e desapropriação de terras, se considerado o recorte temporal desde a década de 1980 até os dias atuais. Entretanto, no decorrer desses anos, foram construindo seus territórios e levantando bandeiras para além da luta pela terra. A luta pela agroecologia se amplia na luta pela Soberania Alimentar e, com isso, surgem programas como o PNAE e o PAA ${ }^{7}$.

Esses programas, no entanto, apresentam problemas e limites na sua implantação, como, por exemplo, recursos muito limitados em relação ao que é distribuído ao PRONAF ou descontinuidade do seu funcionamento, visto que, muitas vezes, são suspensos por problemas nas contas das prefeituras ou das associações dos produtores. Porém, mesmo que persista essa insegurança na chegada dos recursos (MONTENEGRO GÓMEZ, 2015), esses programas têm se apresentado como importantes políticas na busca da soberania alimentar do país.

A Educação do Campo, que já havia sido bandeira de luta desde a década de 1990, ganha seu espaço, adentra as universidades e ganha organizações próprias, que constroem processos de autonomização por meio dessas experiências. Consolidam-se agora, 
dentro das universidades em todas as regiões do país e em diversas áreas do conhecimento, os cursos dos movimentos sociais, via Pronera. Segundo o MST (2010, p. 24),

Por meio de parcerias com universidades públicas, trabalhadores e trabalhadoras rurais do MST estudam em 50 instituições de ensino. Há aproximadamente 100 turmas de cursos formais e mais de 5 mil educandos nessas instituições. São cursos técnicos de nível médio (como Administração de Cooperativas, Saúde Comunitária, Magistério e Agroecologia), cursos superiores e especializações (como Pedagogia, Letras, Licenciatura em Educação do Campo, Ciências Agrárias, Agronomia, Veterinária, Direito, Geografia, História).

Esses cursos formam professores e professoras das Escolas Itinerantes, das escolas de assentamentos rurais do Movimento e formam, também, quadros para a coordenação dos setores em suas diversas escalas. Com isso, a educação marca um papel central da organização escalar do Movimento. Mesmo em um momento político de recuo de ocupações de terras e de prédios públicos, assim como de mobilizações em geral, essas organizações vão se reestruturando, reconfigurando suas escalas por meio dessas outras bandeiras e se ampliando, ao contrário do que se previa sobre o seu fim.

Sendo assim, não podemos nos esquecer da resistência e da recriação campesina, que também se apropria de programas do Governo para transformá-los em espaços de autonomias relativas. Esse é o caso da apropriação do Pronera pelos movimentos sociais que, de 1998 a 2011, promoveu a realização de 320 cursos nos níveis EJA Fundamental, Ensino Médio e Ensino Superior, envolvendo 82 instituições de ensino, 38 organizações demandantes e 244 parceiros, com a participação de 164.894 educandos (II PNERA,-2015).

A configuração da questão agrária na atualidade, a partir desses confrontos e da ampliação das formas de dominação do agronegócio, além dessas ações que mostram a existência de projetos outros de agricultura e de sociedade, mostra-nos que os processos educativos são centrais. A disputa pela subjetivação de quem mora no campo, de quem produz comida, de quem não tem terra e de quem não possui muitas formas de se manter no campo com autonomia é chave nas estratégias de dominação capitalista.

Para exemplificar esse processo, neste artigo, focamos o ProJovem Campo, que entra nessa disputa para forçar uma Educação do Campo "desde cima", desvirtuando e marginalizando a Educação do Campo "desde baixo". Especialmente, escolhemos no material didático veiculado pelo programa em 2009 aspectos concretos, como, por exemplo, a forma de produção e de autorreconhecimento enquanto sujeito do campo. 
Partiremos desses elementos na busca por desconstruir discursos. Para isso, tentaremos adaptar as formas de análise sobre o uso do discurso em Foucault (1987) visando desconstruir a construção textual presente nesse material didático. Compreende-se que há o privilégio de um ou outro conceito, tema ou concepção política na produção desse material e que, portanto, torna-se necessário desvendá-lo na busca de colocar outro discurso em debate: o da Educação do Campo retomando o seu projeto político.

\section{A ANÁLISE DOS DISCURSOS NO MATERIAL DIDÁTICO-PEDAGÓGICO DO PROJOVEM CAMPO - SABERES DA TERRA: A MARGINALIZAÇÃO DE OUTRAS FORMAS DE REPRODUÇÃO SOCIAL NO CAMPO}

"O discurso não tem apenas um sentido ou uma verdade, mas uma história." 8

É perceptível o papel central que a educação possui nas formas de controle e de poder na busca de um modelo de desenvolvimento a ser estabelecido e ampliado. Os programas e as políticas no âmbito da Educação do Campo têm servido para a apropriação e o controle das formas de vida nesses espaços rurais.

Realizamos uma análise dos Cadernos Pedagógicos dos Educadores e Educandos do ProJovem Campo - Saberes da Terra buscando levantar elementos em torno da questão agrária atual, tendo como foco a construção e a recriação dos "novos" sujeitos e da "nova" forma de produção na construção desse "novo rural", elementos centrais da atualidade da questão agrária.

Interessa-nos, portanto, analisar as partes em que esse material trata de moldar o camponês, categorizando-o em agricultor familiar, bem como observar em que fragmentos há esforços em promover a substituição de uma agricultura familiar camponesa ${ }^{9}$ por uma agricultura familiar de mercado. Trata-se de analisar as construções discursivas criadas para a apropriação do Estado, por meio de programas e políticas sob uma lógica do capital.

Nesse sentido, estamos entendendo que o material didático é peçachave na formação dos sujeitos atendidos pelo Programa. Sendo assim, uma análise cuidadosa dos elementos e dos discursos nos ajuda não só a desvendar as formas de apropriação do Estado das demandas da classe trabalhadora rural, como também nos revela os discursos construídos “desde cima”, que são os principais embates da questão agrária hoje.

Em uma análise cuidadosa das obras de Michel Foucault relacionadas aos estudos de análise do discurso, Fischer (2001, p. 199) 
nos fala sobre essa metodologia e sobre o seu uso em um contexto de relações de poder, como o que se apresenta na construção deste artigo.

A conceituação de discurso como prática social já exposta em "A Arqueologia", mas que se torna bem clara em "Vigiar e punir" e na célebre aula "A Ordem do discurso", sublinha a ideia de que o discurso sempre se produziria em razão de relações de poder. E, mais tarde, nos três volumes de sua História da sexualidade, o pensador mostra explicitamente que há duplo e mútuo condicionamento entre as práticas discursivas e as práticas não discursivas, embora permaneça a ideia de que o discurso seria constitutivo da realidade e produziria, como o poder, inúmeros saberes.

Analisar o uso do discurso contido no material didático do ProJovem Campo sob a ótica da lógica do capital na produção de saberes para a implementação do seu modelo de desenvolvimento é o nosso objetivo nesta breve construção analítica. Segundo Foucault (1990, citado por FISCHER, 2001, p. 198),

Para analisar os discursos precisamos antes de tudo recusar as explicações unívocas, as fáceis interpretações e igualmente a busca insistente do sentido último ou do sentido oculto das coisas práticas bastante comuns quando se fala em fazer o estudo de um discurso.

Estamos, dessa forma, a partir da leitura dos Cadernos Pedagógicos do Projovem Campo, tentando entender os elementos discursivos da questão agrária no Brasil hoje, que são reproduzidos de forma escalar e que reduzem as possibilidades de construção de autonomia por meio de ações do Estado, buscando, insistentemente, o sentido dos conceitos e das práticas indicadas nesses materiais didáticos-pedagógicos.

O discurso ultrapassa a simples referência a coisas, existe para além da mera utilização de letras, palavras e frases, não pode ser entendido como um fenômeno de mera expressão de algo: apresenta regularidades intrínsecas a si mesmo, através das quais é possível definir uma rede conceitual que lhe é própria. É a esse mais que o autor se refere, sugerindo que seja descrito e apanhado a partir do próprio discurso, até porque as regras de formação dos conceitos, segundo Foucault, não residem na mentalidade nem na consciência dos indivíduos; pelo contrário, elas estão no próprio discurso e se impõem a todos aqueles que falam ou tentam falar dentro de um determinado campo discursivo. (FISCHER, 2001, p. 200)

Sendo assim, o espaço discursivo delimitado nesta breve análise é: o que os Cadernos Pedagógicos "falam" sobre o sujeito e a forma de produção para o modelo de desenvolvimento do campo hoje no Brasil? Essa delimitação foi selecionada no interior do campo discursivo dos documentos políticos, usados pelo Estado para uma formação específica da classe trabalhadora rural, o qual promove também o apaziguamento dos conflitos da questão agrária hoje. Essa tarefa teve como fim atingir o objetivo de desvendar as formas de apropriação do Estado da Educação 
do Campo e do seu modelo formativo para ampliar suas formas de subordinação ao modelo de desenvolvimento do capital.

Certamente os discursos são feitos de signos; mas o que fazem é mais que utilizar esses signos para designar coisas. É esse mais que os torna irredutíveis à língua e ao ato da fala. É esse mais que é preciso fazer aparecer e que é preciso descrever. (FOUCAULT, 1987, p. 56)

Estamos, portanto, em busca desse "mais" nos discursos criados nas "falas" do material didático desse Programa. Sem ter o interesse de esgotar a metodologia da análise de discurso elaborada por Foucault, questionaremos os fatos imediatos desse discurso, desconstruindo-os e recompondo-os a partir de outros discursos, os da Educação do Campo, que visa construir outros saberes, a partir de outras bases. Como nos propõe o próprio Foucault (1987, p. 30):

E eu mesmo de minha parte, nada farei se não isso: certamente tomarei por marco inicial unidades inteiramente formadas (como a psicopatologia, ou a medicina, ou a economia política); mas não me colocarei no interior dessas unidades duvidosas para estudar-lhes a configuração interna ou as secretas contradições. Não me apoiarei nelas senão para me perguntar que unidades formam; com que direito podem reivindicar um domínio que as especifiquem no espaço e uma continuidade que a individualize no tempo; segundo que leis se formam; sobre o pano de fundo de que acontecimentos discursivos elas se recortam; e se, finalmente, não são, em sua individualidade aceita e quase institucional, o efeito de superfície de unidades mais consistentes. Aceitarei os conjuntos que a história me propõe apenas para questionálos imediatamente; para desfazê-los e saber se podemos recompô-los legitimamente; para saber se não é preciso reconstruir outros; para recolocá-los em um espaço mais geral que, dissipando sua aparente familiaridade, permita fazer sua teoria.

Desnaturalizar conceitos, temas e elementos postos nesse espaço discursivo; questionar os enunciados desse material didático; perguntar-se por que o sujeito desse material é o agricultor familiar, e não o camponês; por que a agricultura familiar de mercado como forma de produção, e não a agroecologia camponesa; quais os interesses desses discursos? Tais questionamentos partem da descrição de acontecimentos do discurso e colocam uma questão principal: "como apareceu um determinado enunciado, e não outro, em seu lugar?” (FOUCAULT, 1987, p. 31).

De qualquer forma trata-se de reconstituir um outro discurso, de descobrir a palavra muda, murmurante, inesgotável, que ainda do interior a voz que escutamos, de restabelecer o texto miúdo e invisível que percorre o interstício das linhas escritas e, às vezes, as desarruma. [...] trata-se de compreender o enunciado na estreiteza e singularidade da situação; de determinar as condições de sua existência, de fixar seus limites de forma mais justa. (FOUCAULT, 1987, p. 31) 
Esse é o nosso intento na análise que segue: desvendar o que esse discurso "desde cima" esconde ao não evidenciar outros. "Percorrer o interstício das linhas escritas" (FOUCAULT, 1987, p. 31) nesses Cadernos Pedagógicos, fixar os limites dessa teoria de um "novo rural" e estabelecer correlações com a luta por Educação do Campo, recuperando seus fundamentos na atualidade da questão agrária brasileira.

\section{A MARGINALIZAÇÃO DE OUTRAS FORMAS DE REPRODUC̣ÃO SOCIAL NO CAMPO: 0 USO DE UM DISCURSO QUE ESCONDE OUTROS}

Por mais que o livro se apresente como um objeto que se tem na mão; por mais que ele se reduza ao pequeno paralelepípedo que o encerra: sua unidade é variável e relativa. Assim que a questionamos, ela perde sua evidência; não se indica a si mesma, só se constrói a partir de um campo complexo de discursos. (FOUCAULT, 1987, p. 52)

Em uma primeira leitura, ou em uma leitura "despercebida", os Cadernos Pedagógicos do ProJovem Campo se mostram como um rico material didático-pedagógico, repleto de boas leituras e imagens, bem redigido e formulado. Apresenta coerência em seus objetivos, respeita a diversidade de gênero e de etnia e traz boas indicações de atividades a serem realizadas com os alunos.

Mas o que devemos questionar é para quem serve esse material? A quem serve seu discurso? Na prática, em uma pesquisa realizada em comunidades que atenderam a turmas do ProJovem Campo na Paraíba ${ }^{10}$, o que se evidencia é a reclamação frequente de professores e alunos do programa sobre o distanciamento entre o nível de compreensão exigido do aluno para interpretar o material e o nível de compreensão dos alunos matriculados no programa, em sua maioria jovens que passaram pela primeira fase de um Ensino Fundamental deficiente e concluído há bastante tempo, tornando-se semianalfabetos ou analfabetos funcionais.

Além disso, em uma segunda leitura mais atenta e analítica, percebemos que esse material está sobrecarregado de um discurso que é político e ideológico, o qual procuraremos desconstruir com o objetivo de descobrir os discursos que são negados ao se privilegiarem outros. Nas palavras de Foucault (1987, p. 31), "de estabelecer suas correlações com os outros enunciados a que pode estar ligado, de mostrar que outras formas de enunciação ele exclui".

A análise desse material didático nos proporciona a possibilidade de visualizar, na prática, como se dão as formas de controle por meio da educação, da formação e de documentos do próprio Estado. Várias são as ferramentas utilizadas, em uma lógica multidimensional, para 
impor um modelo de desenvolvimento de reprodução ampliada do capital. Esse material didático é, como costumamos dizer, apenas a "ponta" desse processo, que é muito mais amplo.

Iniciemos, pois, com a apresentação do eixo articulador dos Cadernos Pedagógicos: a Agricultura Familiar e a Sustentabilidade. Esse eixo articulador está formado por cinco eixos temáticos, a saber: Agricultura Familiar; Sistemas de Produção; Cidadania; Economia Solidária; e Desenvolvimento Sustentável. Esses são, portanto, os enunciados centrais do discurso desse material didático-pedagógico, e é a partir deles que se derivará um leque de temas encobertos de um campo discursivo do modelo de desenvolvimento do capital para o campo. Interessa-nos, dentre esses temas, os referentes à construção do "novo" sujeito, o agricultor familiar, e sua forma de produção, visto que esses são processos de apropriação de subjetividades dados através da dominação.

Dito de outra forma, estamos desvendando, no material didático, o discurso que se apropria de processos de subjetivação política, ou seja, do processo de tornar-se sujeito enquanto camponês, a qual é uma categoria eminentemente política, em contraposição à análise do sujeito transformado e apropriado pelo modelo de desenvolvimento do capital.

Em uma olhada mais geral no documento, faz-se interessante observar que tanto o eixo articulador como seus eixos temáticos, já citados acima, coincidem com os objetivos e os parâmetros de um "novo" modelo de desenvolvimento rural, o que pode ser observado, por exemplo, nas diretrizes do Programa de Desenvolvimento Sustentável de Territórios Rurais, um dos maiores programas no campo hoje operacionalizados pelo Ministério de Desenvolvimento Agrário - MDA:

As estratégias de apoio ao desenvolvimento sustentável dos territórios rurais têm como diretrizes para a sua implementação nos territórios:

- Adotar a abordagem territorial como referência conceitual para a promoção do Desenvolvimento Rural Sustentável;

- Compreender o território como espaço socialmente construído, lugar de manifestação de diversidades culturais e ambientais que expressam limites e potenciais para a promoção do desenvolvimento rural sustentável;

- Entender o desenvolvimento sustentável dos territórios rurais como um processo que articula, de maneira integrada, as dimensões sociocultural, políticoinstitucional, econômica e ambiental;

- Valorizar ações que estimulem a participação da diversidade de atores sociais nos processos de elaboração, planejamento, implementação e gestão do desenvolvimento sustentável dos territórios rurais, considerando as dimensões de gênero, etnia, geração e raça. (BRASIL, 2004) 
Esses objetivos também estão traçados por instituições internacionais como o Banco Mundial, uma das principais instituições de controle da estrutura escalar "desde cima". Segundo Vilela (1997, p. 4):

Uma importante concepção, a respeito da agricultura brasileira, está posta de forma clara e objetiva pelo Banco Mundial, desafiando o pensamento analítico dos sociólogos e economistas rurais. Como uma das mais importantes instituições multilaterais concebem - no contexto de uma nova divisão internacional do trabalho - um projeto de agricultura nacional para o Brasil? Não resta dúvidas de que o "panode-fundo" destas análises passa pelo processo de globalização, tanto do ponto de vista dos limites e possibilidades de uma política nacional quanto da sua inserção na nova divisão internacional do trabalho, mais conhecida como pós-fordista. Assim, tornase necessário ampliar os horizontes da reflexão para além das fronteiras nacionais e pensar como a agricultura do terceiro mundo entra no novo "regime alimentar".

Tendo isso claro, partimos para as análises dos sujeitos e de sua forma de produção na perspectiva desse material didático. Logo na apresentação do material para o aluno, no Caderno 01 do Educando, desenha-se a sua perspectiva de formação, de construção de um "novo" sujeito, de uma "nova" forma de produção, a qual, na concepção desse material, está atrelada à agroindústria, aos sistemas de cultivo e de criação, extrativismo e aquicultura:

Os estudos aqui propostos serão desenvolvidos de maneira muito interessante. Será uma grande pesquisa didática (docente e discente) desenvolvida ao longo de dois anos letivos. Essa pesquisa pretende construir uma nova noção de AGRICULTURA FAMILIAR SUSTENTÁVEL. Mas, ao tempo em que se constrói a nova noção de Agricultura Familiar Sustentável, quer garantir a todos/ as os/as participantes do ProJovem Campo - Saberes da Terra o certificado de Ensino Fundamental, uma iniciação profissional em cinco ocupações (Sistemas de Cultivo, Sistemas de Criação, Extrativismo, Aquicultura e Agroindústria). (BRASIL. MEC, Caderno 01 do Educando, 2010, p. 13)

Ainda na apresentação desse material, aparece o desejo de formação de uma família rural capitalizada:

Esperamos que esta coletânea de leituras ajude no equacionamento dos problemas que a Agricultura Familiar vive no Brasil e contribua para que a capitalização da família rural garanta um futuro brilhante a todas e todos vocês. (BRASIL. MEC, Caderno 01 do Educando, 2010, p. 11)

O que observamos em seguida é que o termo "camponês" não aparece de modo central no material, nem enquanto sujeito social no campo, nem como uma identidade política. O termo utilizado para os sujeitos dos Cadernos Pedagógicos do ProJovem Campo é "agricultor familiar".

A problemática a ser pesquisada no Eixo Temático 1 será a identidade cultural da Agricultura Familiar, das agricultoras, dos agricultores familiares e dos 
jovens membros dessas famílias. Identidade, nesse eixo, é vista especialmente nas dimensões de gênero, de geração e de etnia, bem como nas relações entre o campo e a cidade. Dimensões da configuração cultural da Agricultura Familiar e de seus membros. (BRASIL. MEC, Caderno 01 do Educador, 2010, p. 58)

No material didático, o agricultor familiar é entendido, segundo as formulações de seus principais ideólogos, como Ricardo Abramovay (citado por BRASIL, 2010):

Se quisermos combater a pobreza, precisamos, em primeiro lugar, permitir a elevação da capacidade de investimento dos mais pobres. Além disso, é necessário melhorar sua inserção em mercados que sejam cada vez mais dinâmicos e competitivos. (BRASIL. MEC, Caderno 03 do Educando, 2010, p. 149, grifo nosso)

\section{A Agricultura Familiar aparece com essa concepção do "novo rural" no campo:}

A agricultura familiar não é uma categoria social recente, nem a ela corresponde uma categoria analítica nova na sociologia rural. No entanto, sua utilização, com o significado e abrangência que the tem sido atribuído nos últimos anos, no Brasil, assume ares de novidade e renovação. (BRASIL. MEC, Caderno 03 do Educando, 2010, p. 147)

Como forma de produção, a Agricultura Familiar é considerada, no material didático, como um caminho natural ao desenvolvimento:

A opção pela Agricultura Familiar se justifica pela sua capacidade de geração de emprego (da família e de outros) e renda a baixo custo de investimento. A sua capacidade de retenção da população fora dos grandes centros urbanos é fator fundamental na construção de alternativas de desenvolvimento. Sua capacidade de produzir alimentos a menor custo e, potencialmente, com menores danos ambientais, impulsiona o crescimento de todo o entorno socioeconômico local. (BRASIL. MEC, Caderno 01 do Educando, 2010, p. 72)

O discurso do material relaciona a Agricultura Familiar às atividades produtivas de monocultivo, como a cana, o café e o milho, e às relações de assalariamento no regime de produção do agricultor familiar:

Catende-Harmonia ${ }^{11}$ vem desenvolvendo projetos em parceria com diversas organizações no sentido do estímulo a novas atividades produtivas no âmbito da agricultura familiar e da diversificação dos derivados da cana, combinando sustentabilidade ambiental e justiça social às iniciativas.

Atualmente 4 mil trabalhadores utilizam produtivamente cerca de 5.100 hectares em culturas agrícolas e animais em regime de agricultura familiar. Esse mesmo contingente utiliza produtivamente cerca de 5.250 hectares em regime de produção assalariada no plantio da cana, do café e do milho. (BRASIL. MEC, Caderno 04 do Educando, 2010, p. 87)

As relações de trabalho aparecem como forma de produção e geração de renda: "As relações de trabalho na Agricultura Familiar, 
considerando suas especificidades de produção, geração de renda e possibilidades de sua reorganização para construção da sustentabilidade solidária” (BRASIL. MEC, Caderno 01 do Educando, 2010, p. 11).

A diversidade camponesa e as diversas identidades no campo são substituídas por uma cultura única, que é a do agricultor familiar:

Também será muito interessante pensar diferentes formas para que sejam apresentadas as manifestações culturais características de sua região, sem esquecer dos produtos - cultivos, criações, artesanatos, entre outros - desenvolvidos pelos agricultores e agricultoras familiares do estabelecimento, assentamento, comunidade, etc. (BRASIL. MEC, Caderno 04 do Educador, 2010, p. 58)

O sujeito agricultor familiar aparece sempre atrelado às relações de produção, comercialização e mercado: "Refletir sobre as relações entre os modos de produção, seus processos de circulação, comercialização, consumo e suas implicações na vida dos/as agricultores/as familiares" (BRASIL. MEC, Caderno 04 do Educador, 2010, p. 63).

Ainda, ao analisar o trecho que contém o relato de um Técnico em Agropecuária, o material acrescenta elementos à perspectiva do sujeito agricultor familiar vinculado diretamente à lógica de mercado:

O fragmento da intervenção de Antônio Carlos no vídeo é significativo para a introdução da discussão sobre Sistemas de Produção e Agriculturas Familiares.

O Técnico traz na sua fala uma reflexão importante sobre a forma como os agricultores familiares muitas vezes vão sendo organizados, a partir de uma lógica de mercado, no sentido da especialização do seu sistema produtivo. (BRASIL. MEC, Caderno 02 do Educando, 2010, p. 28)

Por meio do material, o aluno é posto a refletir sobre as atividades do agricultor familiar:

Refletir sobre as atividades de cultivo, de criação animal, de aquicultura e extrativistas que os/as agricultores/as familiares desenvolvem, relacionando-as com a organização mais geral do seu sistema família-estabelecimento e com sua sustentabilidade econômica e ecológica;

Conhecer os processos de beneficiamento da produção familiar, bem como refletir sobre a influência das grandes agroindústrias que estão instaladas na região. (BRASIL. MEC, Caderno 02 do Educando, 2010, p. 74)

Os dois modelos de desenvolvimento ficam claros no recorte abaixo. De um lado está o agronegócio, do outro, a agricultura familiar. Essa combinação é apontada como a única possível dentro de um projeto de desenvolvimento no campo.

A partir desse momento, os/as educandos/as podem elaborar quadros apontando as especificidades e diferenças entre os modelos produtivos da agricultura familiar e do agronegócio na apropriação dos recursos naturais, no sentido de identificar as características, contradições, avanços, conquistas e limites de ambos os projetos de 
desenvolvimento, os pontos de conflito entre eles e os impactos ambientais por eles gerados no ambiente local. (BRASIL. MEC, Caderno 05 do Educador, 2010, p. 76)

Acrescenta-se a isso a regulação de instituições de controle "desde cima", em escala internacional, como a FAO, ou nacional, como o INCRA, as quais reconhecem esses dois "claros" modelos de campo para o Brasil, naturalizando-os:

Este segundo enfoque tem escolhido a agricultura familiar como um dos seus pilares chaves. Uma pesquisa realizada pela FAO (Organização das Nações Unidas para Agricultura e Alimentação) e pelo INCRA (Instituto Nacional de Colonização e Reforma Agrária), cujo objetivo principal era estabelecer as diretrizes para um "modelo de desenvolvimento sustentável", escolheu-se como forma de classificar os estabelecimentos agropecuários brasileiros a separação entre dois modelos: "patronal" e "familiar". Os primeiros teriam como característica a completa separação entre gestão e trabalho, a organização descentralizada e ênfase na especialização. $\mathrm{O}$ modelo familiar teria como característica a relação íntima entre trabalho e gestão, a direção do processo produtivo conduzido pelos proprietários, a ênfase na diversificação produtiva e na durabilidade dos recursos e na qualidade de vida, a utilização do trabalho assalariado em caráter complementar e a tomada de decisões imediatas, ligadas ao alto grau de imprevisibilidade do processo produtivo. ${ }^{12}$ (BRASIL. MEC, Caderno 03 do Educando, 2010, p. 148)

No centro do seu discurso está também a adequação desses sujeitos e a sua forma de produção às políticas e aos programas do Governo Federal, como se essa fosse a única solução para a recriação dos sujeitos no campo: a sua inserção a territórios construídos pelo Estado e as políticas direcionadas a eles, homogeneizando espaços, como é o caso dos Territórios da Cidadania.

Foram definidos conjuntos de municípios unidos pelas mesmas características econômicas e ambientais que tenham identidade e coesão social, cultural e geográfica. Maiores que o município e menores que o estado, os Territórios da Cidadania conseguem demonstrar, de uma forma mais nítida, a realidade dos grupos sociais, das atividades econômicas e das instituições de cada localidade, o que facilita o planejamento de ações governamentais para o desenvolvimento dessas regiões. (BRASIL. MEC, Caderno 05 do Educando, 2010, p. 116)

Sobre as políticas e os programas, mostra uma visão reduzida do Governo Federal, acrescentando, ainda:

O Governo Federal nos últimos anos tem desenvolvido importantes políticas de juventude no país. O Guia de Políticas Públicas de Juventude (2006) enfoca os Programas governamentais. Destaca-se, no que se refere à juventude do campo, o Programa PRONAF Jovem, Programa Minha Primeira Terra e o Saberes da Terra.

A institucionalização da política nacional de juventude é um elemento histórico no Brasil, considerando-se que até então, no Brasil, ainda não havia esse registro de elaboração, articulação e implementação de políticas públicas de juventude integradas. (BRASIL. MEC, Caderno 05 do Educando, 2010, p. 146) 
Esses são alguns dos recortes dos Cadernos Pedagógicos do ProJovem Campo (BRASIL, 2010) que nos dão um panorama razoável para conhecer o discurso político-ideológico ali contido. Nesses recortes, percebemos um discurso central em torno do elemento principal que queremos desvendar na construção discursiva do material: o discurso do desenvolvimento. Para esse material, o desenvolvimento é algo indiscutível e o único caminho a ser seguido. Esse desenvolvimento se divide, no material, em dois projetos possíveis: o do agronegócio e o da agricultura familiar.

Com isso, esse discurso constrói um "ideal" de campo, no qual ambos os projetos e todos os sujeitos podem conviver harmonicamente e sem conflitos. Nesse sentido, dentro da construção discursiva desse modelo produtivo, a questão agrária estaria resolvida.

Os elementos, na nossa análise, os quais relacionam-se ao sujeito e à sua forma de produção no campo, apresentam-se nessa construção discursiva a partir da negação do uso de conceitos políticos da luta pela terra, como agroecologia e campesinato, os quais não aparecem como temas centrais nesse material.

Incorpora-se a esse discurso a ideia de um "novo regime alimentar", que tem como sujeito produtivo o agricultor familiar inserido na lógica do mercado, sendo ele capaz de realizar uma suposta forma sustentável de produzir. Esses elementos compõem o eixo central da construção discursiva desse modelo de desenvolvimento no material e relegam a um segundo plano a diversidade de sujeitos e de suas formas produtivas.

Falamos de suposta forma sustentável do agricultor familiar porque, com a sua entrada no mercado, mesmo em suas terras, esses sujeitos devem seguir parâmetros produtivos designados pelas empresas. Lembremo-nos, por exemplo, do modelo de contratação por compra e venda do produto, modelo "carro-chefe" da agricultura familiar de mercado.

Podemos dar como exemplo a seguinte situação: a família que passa a criar frangos de granja para a Sadia, hoje BRF S. A., sendo essa uma das alternativas do camponês ao ingressar em programas da agricultura familiar do Governo, para se inserir nessa forma produtiva, essa família deixa a sua forma de criar galinhas em galinheiros e, em certos momentos, à solta no quintal, para criar frangos de granja em um galpão fechado, em condições de total insalubridade para esses animais e para seus cuidadores, os quais serão membros dessa família. Nessa forma de criação de animais, também se deixa de alimentá-los com a sobra de alimentos da casa, principalmente de verduras, como é mais comum, e passa-se a alimentá-los com ração, o que altera o seu organismo, proporcionando um rápido crescimento das aves.

Nesse pequeno exemplo, no qual poderíamos continuar citando inúmeras mudanças sofridas pelo camponês no simples processo de 
deixar de criar galinhas para criar frangos de granja, podemos observar claramente a perda de autonomia na produção e o distanciamento da forma produtiva camponesa. Esta é usurpada pela lógica do mercado. Nesse mesmo sentido, a educação proposta por esses programas vem naturalizando essas formas de produção e transformando-as em única alternativa para esses sujeitos, que invariavelmente devem se tornar agricultores familiares capitalizados. Isso, no entanto, é uma forma encoberta de selecionar apenas uns poucos que vão conseguir triunfar e descartar muitos que ficarão à disposição como mão de obra barata.

A substituição do uso do termo camponês pelo termo agricultor familiar não só marca as transformações das políticas educativas no Brasil na entrada do século XXI, como também direciona as normas para o pequeno agricultor e suas formas de vida por meio de outras ações do Estado. Autores como José Eli da Veiga (1996), Ricardo Abromovay (1999) e José de Souza Martins (2001) entraram em uma disputa conceitual para a apropriação da "nova" categoria de agricultor familiar.

Essa linha de pensamento veio sobrecarregada de uma leitura mais técnica desse "novo sujeito". Porém, em seu discurso, ela vem encoberta de sentidos políticos que respondem à nova postura da demanda internacional de mercado, mostrando, assim, que o camponês que não está inserido no mercado não receberá os mesmos benefícios do Estado e, sem "nenhuma" outra saída, ele deve se integrar a esse modelo. Programas como o ProJovem Campo estão aí para mostrar que esse é o "único" caminho possível, discurso este que se naturaliza por meio do seu material didático.

Dessa forma, para as organizações em torno da Educação do Campo, definir as categorias de camponês ou agricultor familiar é um campo em disputa, que tem gerado conflitos no âmbito da questão agrária brasileira. Para os pesquisadores e os movimentos sociais organizados:

\footnotetext{
No caso da Educação do Campo, manter a contradição instalada significa continuar sua trajetória sendo fiel ao seu percurso original de vínculo com os "pobres do campo" e com suas organizações e lutas sociais. Porque é desses sujeitos (que hoje "lutam pra deixar de morrer") que estão nascendo/podem nascer experiências, alternativas, que recolocam a perspectiva de construção social dominante, hegemônica e recolocam a perspectiva de construção social para "além do capital". É disso que se trata na questão da resistência política, econômica e cultural do campesinato, de uma outra lógica de trabalho no campo que não o assalariamento, que não a agricultura do negócio. (CALDART, 2008, p. 76)
}

Dessa forma, usar determinado termo para identificar os sujeitos do processo formativo desse material pedagógico também implica escolher um dos lados nesse espaço em disputa. Negar o sujeito camponês por 
meio da substituição desse termo por agricultor familiar é uma questão política que está em debate no interior da questão agrária hoje.

\section{CONSIDERAÇ̃̃ES FINAIS}

Manter a luta dos movimentos sociais viva, e assim a contradição vivida pelos seus sujeitos incorporada dentro da proposta educativa e formativa da Educação do Campo, é dizer não a um modelo de agricultura familiar construído pelo Banco Mundial e as demais instituições internacionais. É também resistir e continuar construindo processos de subjetivação política por meio da autonomização dos próprios sujeitos.

Entendemos, segundo Caldart et al. (2012), que uma verdadeira Educação do Campo deve ter como base uma formação que negue as estruturas de uma agricultura familiar de mercado e os ditames do capital; que valorize o camponês e seus saberes; e que tenha como centro das discussões a agroecologia e a justiça social, conformando uma questão agrária em que esses elementos estão em disputa na construção discursiva, nas estruturas escalares "desde cima", mas também "desde baixo".

Sobrecarregar esse material didático com conceitos prontos e naturalizados, como se esses não fossem espaços em disputa da questão agrária atual, apontando determinadas questões como resolvidas e apaziguando os conflitos, significa esconder o visível, por meio de conceitos fetichizados, revestidos de uma falsa "boa intenção". Significa construir um processo formativo que se distancia de um saber para a emancipação e a formação humana.

O material didático do ProJovem Campo joga com a apropriação de conceitos e temas-chave da questão agrária hoje, transformando-os em formas de subordinação por meio do uso do discurso. O objetivo, com essas formas de apropriação do Estado, é construir e reconstruir o capital e suas formas de controle escalarmente "desde cima", não deixando espaços para a construção de ações de autonomização "desde baixo". Mas tem também, sob uma lógica territorial do poder que, em primeira instância, faz-se necessária para a reprodução do capital, o objetivo de se apropriar das subjetividades desses sujeitos "desde baixo", que são construídas em processos de luta e resistência camponesa, limitando suas formas de vida, de trabalho, de saberes e de reprodução social a um modelo específico, vinculado à agricultura familiar.

Entretanto, o projeto político da Educação do Campo também possui o seu discurso e é ele que deve ser retomado e recolocado nos materiais didáticos das propostas educativas para o campo, com o objetivo de alterar as bases estruturais montadas pelo capital no 
campo. O projeto da Educação do Campo deve ser retomado visando à reapropriação das demandas da classe trabalhadora apropriadas pelo Estado e transformando-as em ações voltadas para as autonomias relativas, por meio de uma organização escalar de poder.

Énesse sentido que reconhecemos a necessidade de desconstruir o discurso de desenvolvimento hegemônico, apontado pelo Estado por meio de seus programas e políticas. Para isso, é preciso colocar em seu lugar um outro discurso, que está atrelado à reconstrução da política no campo por meio da educação, renovando, assim, a questão agrária brasileira sob uma ótica da construção de estruturas escalares de poder e de contrapoder e de ações de subordinação e de autonomia.

\section{REFERÊNCIAS}

ABRAMOVAY, Ricardo. Agricultura familiar e desenvolvimento territorial. Reforma Agrária (Revista da Associação Brasileira de Reforma Agrária), v. 28, n. 29, n. 1, jan./ago., 1999. ANDRADES, Thiago Oliveira de; GANIMI, Rosângela Nasser. Revolução verde e a apropriação capitalista. CES Revista, Juiz de Fora, v. 21, n. 01, p. 43-56, 2007.

BRASIL. Ministério do Desenvolvimento Agrário - MDA. Secretaria de Desenvolvimento Territorial - SDT. Referências para o apoio ao desenvolvimento territorial, 2004 (Mimeo). BRASIL. Ministério da Educação - MEC. Secretaria de Educação Continuada, Alfabetização e Diversidade - SECAD; Secretaria de Educação Profissional e Tecnológica - SETEC. Projeto-Base ProJovem Campo - Saberes da Terra. Programa Nacional de educação de jovens agricultores(as) familiares integrada à qualificação social e profissional. Brasília: MEC/Secad; Setec, 2009.

BRASIL. Ministério da Educação - MEC. Caderno Pedagógico Educadoras e Educadores. Agricultura Familiar Identidade, Cultura, Gênero e Etnia. Coleção Cadernos Pedagógicos ProJovem Campo-Saberes da Terra. Coordenação: Armênio Bello Schmidt, Sara de Oliveira Silva Lima, Wanessa Zavarese Sechim - Brasília: Ministério da Educação, Secretaria de Educação Continuada, Alfabetização e Diversidade, 2010.

CALDART, Roseli Salete. Pedagogia do Movimento Sem-Terra. 3. ed. São Paulo: Expressão Popular, 2004.

CALDART, Roseli Salete. Educação do campo: notas para uma análise de percurso. In: Trab. educ. saúde, Rio de Janeiro, v. 7, n.1, 2009, p. 35-64.

CALDART, Roseli Salete. (Org.) Dicionário da Educação do Campo. São Paulo: Expressão Popular, 2012.

FAO - ORGANIZAÇÃO DAS NAÇÕES UNIDAS PARA A AGRICULTURA E ALIMENTAÇÃO; INCRA - INSTITUTO NACIONAL DE COLONIZAÇÃO E REFORMA AGRÁRIA. Diretrizes de Política Agrária e Desenvolvimento Sustentável. Versão resumida do Relatório Final do Projeto UTF/BRA/036. Brasília, mar. 1994.

FISCHER, Rosa Maria Bueno. Foucault e a análise do discurso em educação. Cadernos de Pesquisa, n. 114, p. 197-223, nov. 2001.

FOUCAULT, Michel. A Arqueologia do Saber. 3. ed. Tradução de Luiz Felipe Baeta Neves. Rio de Janeiro: Forense Universitária, 1987. 
HARVEY, David. A produção capitalista do espaço. Tradução de Carlos Szlak. Coordenação de Antônio Carlos Robert Moraes. São Paulo: Annablume, 2005.

MONTENEGRO GÓMEZ, Jorge Ramón. Reconversión silenciosa de la producción y comercialización campesina: lectura multiescalar de las políticas públicas implementadas en Brasil. Revista Geonordeste, São Cristóvão, v. 26, n. 1, p. 124-149, jan./jul. 2015.

MARTINS, José de Souza. Os camponeses e a política no Brasil. 5. ed. Petrópolis-RJ: Editora Vozes, 2001.

MST. Lutas e conquistas: reforma agrária: por justiça social e soberania popular. São Paulo: Secretaria Nacional do MST, 2010.

II PNERA - Relatório da II Pesquisa Nacional sobre Educação na Reforma Agrária. INCRA. PRONERA. UNESCO. UNESP. IPEA. Secretaria de Assuntos Estratégicos. MDA. 2015.

SILVA, José Francisco Graziano da; STOLCKE, Verena. (Org.). A Questão Agrária: Weber, Engels, Lênin, Kautsky, Chayanov, Stalin. São Paulo: editora brasiliense, 1981.

SILVA, José Francisco Graziano da. O novo rural brasileiro. Nova Economia, Belo Horizonte, v. 7, n. 1, maio 1997. p. 43-81.

VEIGA, José Eli da. Agricultura familiar e sustentabilidade. Cadernos de Ciência \& Tecnologia, v. 13, n. 3, 1996, p. 383-404.

VILELA, Sérgio Luís Oliveira. Qual política para o campo brasileiro? (Do Banco Mundial ao Pronaf: a trajetória de um novo modelo?). In: CONGRESSO DA SOBER, 35, Mimeo. Natal, 1997.

\section{NOTAS}

${ }^{1}$ Em 2008, o Programa Saberes da Terra foi incorporado ao Programa Nacional de Inclusão de Jovens - ProJovem, objetivando "promover a reintegração de jovens ao processo educacional, sua qualificação profissional e seu desenvolvimento humano e cidadão" (BRASIL, 2009, p. 6). Desde 2008, o Programa teve 19 projetos aprovados em diferentes estados do Brasil. O funcionamento desses projetos em cada estado ocorreu, a partir de então, por meio de uma parceria entre MEC/SECAD, Instituições de Ensino Superior, Governos dos Estados e Prefeituras Municipais. Segundo dados da Coordenação de Educação do Campo, as metas para o atendimento do ProJovem Campo - Saberes da Terra foi de 224 mil jovens agricultores(as) familiares, sendo 35 mil para a edição 2008, 24 mil, em 2009, 80 mil, em 2010, e 85 mil, em 2011.

${ }^{2}$ Estamos falando do Capital e suas diversas facetas no momento histórico atual, como em sua espacialidade no rural. Estamos falando do agronegócio, dos grandes empresários no campo hoje, das grandes corporações que controlam o acesso às sementes e às formas de produção.

${ }^{3}$ Referimo-nos aos subordinados ao capital em suas variadas formas e processos de subordinação no campo. São os camponeses expropriados de suas terras, os sem-terra, os camponeses excluídos do acesso aos recursos do Estado, as comunidades tradicionais esquecidas e, quando reconhecidas, colocadas à margem da história. São todos aqueles sujeitos do campo a quem se nega o direito de construção de sua própria autonomia.

${ }^{4}$ Em uma lógica territorial do poder, segundo Harvey (2005, p. 34), o homem de Estado refere-se a esse como sujeito construtor de uma lógica territorial do poder) procura vantagens coletivas, vendo-se restringido pela situação política e militar de seu Estado, sendo em algum 
sentido responsável perante uma comunidade de cidadãos ou, o que é mais frequente, perante um grupo de elite, uma classe, uma estrutura de parentesco ou algum outro grupo social.

${ }^{5} \mathrm{O}$ "pacote tecnológico" da Revolução Verde envolve tecnologias como: mecanização, uso de variedades vegetais geneticamente melhoradas (para obtenção de alto rendimento), fertilizantes de alta solubilidade, pesticidas, herbicidas e irrigação (ANDRADES; GAMINI, 2007).

${ }^{6} \mathrm{O}$ Banco da Terra, programa de crédito fundiário do Ministério do Desenvolvimento Agrário, financia aos pequenos empreendedores rurais a compra de imóveis rurais e a implantação de obras de infraestrutura básica, como construção ou reforma de residência, disponibilização de água para consumo humano e animal, construção de estradas, rede interna de eletrificação, abertura, recuperação ou construção de vias de acessos internos e construção ou reforma de cercas. Os beneficiários do programa contam também com o crédito produtivo concedido pelo Pronaf (Disponível em: < http://www2.prsc.mpf.mp.br/conteudo/servicos/noticiasascom/ultimas-noticias-anteriores/2003/abr/banco-da-terra-sc $>$. Acesso em: 6 out. 2014).

${ }^{7}$ O Programa Nacional de Alimentação Escolar-PNAE é um programa do governo federal que tem por objetivo oferecer alimentação saudável aos milhões de estudantes das escolas públicas de todo o Brasil. Tem como principal objetivo a melhoria das condições de aprendizagem, ensinar práticas alimentares saudáveis aos alunos por meio de ações de educação alimentar e de alimentos que supram as necessidades nutricionais. O Programa de Aquisição de AlimentosPAA tem por objetivo a aquisição de produtos da agricultura familiar, com a finalidade de atender à demanda de alimentos de populações em condição de insegurança alimentar. Os participantes, agricultores enquadrados no PRONAF, devem preferencialmente estar organizados através de grupos formais (cooperativas e associações) (MONTENEGRO GÓMEZ, 2015, p. 130)

${ }^{8}$ FOUCAULT, 1987, p. 146.

${ }^{9}$ No texto "Sobre a teoria dos sistemas econômicos não capitalistas", Chayanov (1981) nos aporta importantes elementos a serem considerados em uma análise da produção familiar camponesa e uma produção capitalista. O autor explica: "o produto do trabalho indivisível de uma família, e por conseguinte a prosperidade da exploração familiar não aumentam de maneira tão marcante quanto o rendimento de uma unidade econômica capitalista influenciada pelos mesmos fatores, porque o camponês trabalhador, ao perceber o aumento da produtividade do trabalho inevitavelmente equilibrará os fatores econômicos internos de sua granja, ou seja, com menor auto-exploração de sua capacidade de trabalho. Ele satisfaz melhor as necessidades de sua família, com menor dispêndio de trabalho, e reduz assim a intensidade técnica do conjunto de sua atividade econômica". Chayanov continua o seu texto resgatando elementos que diferenciam a unidade de produção de base camponesa. Para ver mais sobre os posicionamentos desse autor, ver: SILVA; STOLCKE, 1981.

${ }^{10}$ Esse artigo é parte da pesquisa realizada durante a construção da nossa tese de doutorado intitulada "As políticas públicas em educação do campo, entre a subordinação e a autonomia: o PROJOVEM campo - saberes da terra e sua implantação na Paraíba no contexto da questão agrária", defendida em março de 2015 na UFPR-Curitiba, pelo Programa de Pós-Graduação em Geografia, sob a orientação do professor Dr. Jorge Ramón Montenegro Gómez.

11 O material estava apresentando a experiência da Cooperativa de Produção Agroindustrial Catende-Harmonia. Catende-Harmonia constitui uma das mais importantes experiências em economia solidária e autogestão do Brasil. Segundo o Caderno 04 do Educando, a Catende-Harmonia vem desenvolvendo projetos em parceria com diversas organizações no sentido do estímulo.

${ }^{12}$ Cf. FAO; INCRA, 1994. 
Submetido: $18 / 05 / 2016$

Aprovado: 29/05/2017

Contato:

Mara Edilara Batista de Oliveira

Rua Marques de Barbacena, 38, ap 101. Verolme

Angra dos Reis $\mid$ RJ | Brasil

CEP 23.510-050 